\title{
Reducing Postharvest Losses of Spinach Stored at Nonoptimum Temperatures with the Implementation of Passive Modified Atmosphere Packaging
}

\author{
Konstantinos G. Batziakas \\ Department of Horticulture and Natural Resources, Kansas State University, \\ 22201 West Innovation Drive, Olathe, KS 66061 \\ Shehbaz Singh \\ Curation Foods Inc., 2811 Airpark Drive, Santa Maria, CA 93455
}

Kanwal Ayub and Qing Kang

Department of Statistics, Kansas State University, 101 Dickens Hall, 1116 Mid-Campus Drive N., Manhattan KS 66506-0802

Jeffrey K. Brecht

Horticultural Sciences Department, University of Florida, 2550 Hull Road, Gainesville, FL 32611

\section{Cary L. Rivard and Eleni D. Pliakoni \\ Department of Horticulture and Natural Resources, Kansas State University, 22201 West Innovation Drive, Olathe, KS 66061}

Additional index words. food loss, food waste, MAP, quality, shelf life, Spinacia oleracea, temperature abuse

\begin{abstract}
Postharvest losses of fresh produce constitute the biggest portion of the total food losses occurring in food chains globally. The main driver behind the postharvest losses of fresh fruits and vegetables is temperature abuse occurring mainly during transportation and storage. This is a particular problem for small-acreage producers, who frequently have limited access to postharvest handling resources like optimum refrigeration conditions. Passive modified atmosphere packaging (MAP) is a relatively inexpensive intervention that does not require specialized equipment and has demonstrated some potential for maintaining the quality and extending the shelf life of fresh produce stored in nonoptimum temperatures. Our objective was to determine the effect of passive MAP on the quality and storage life of spinach (Spinacia oleracea cv. Corvair) when stored in nonoptimum temperatures. Mature spinach leaves ( $\approx 320 \mathrm{~g})$ were packaged in passive MAP bags, developed using the BreatheWay technology, and nonMAP produce bags and subsequently stored at 13 or $21^{\circ} \mathrm{C}$. Spinach physical and nutritional quality was evaluated throughout its storage life in terms of overall quality, water loss, leaf tenderness, surface color, chlorophyll content, electrolyte leakage, chlorophyll fluorescence, antioxidant capacity, total phenolic content, and vitamin $\mathrm{C}$ content. Spinach that was stored in MAP bags reached headspace equilibrium at $\approx 6 \%$ $\mathrm{O}_{2}$ and $11 \% \mathrm{CO}_{2}$ at $13{ }^{\circ} \mathrm{C}$ and $\approx 4 \% \mathrm{O}_{2}$ and $8 \% \mathrm{CO}_{2}$ at $21{ }^{\circ} \mathrm{C}$ after 2 days of storage for both temperatures. The spinach stored in passive MAP at 13 or $21{ }^{\circ} \mathrm{C}$ demonstrated significantly higher overall quality during storage and 2 and 1 day longer storage life, respectively, when compared with the control. The spinach in passive MAP demonstrated a slower rate of yellowing and water loss during storage. The limiting factor for the spinach stored in MAP was decay due to condensation at $13^{\circ} \mathrm{C}$ and yellowing at $21^{\circ} \mathrm{C}$. There were no statistical differences in the examined nutritional quality parameters between the spinach stored in MAP and produce bags. This study shows that passive MAP can be a valuable tool for reducing the food losses occurring in small-acreage fruit and vegetable operations that have limited access to cooling and refrigerated storage.
\end{abstract}

The global food demand is constantly rising and is expected to increase by $110 \%$ in 2050 (Mc Carthy et al., 2018) due to the increase in global population and the improvement of the standard of living around the globe (Mc Carthy et al., 2018; Porat et al.,
2018). However, there are concerns about the ability of agricultural food systems to satisfy this increase in demand (Conijn et al., 2018; Davis et al., 2016). Reducing food losses and waste (FLW) is a major component of the efforts for achieving global food security
(Porat et al., 2018). Approximately 30\% to $50 \%$ of the food produced globally for human consumption is lost or wasted (Myers et al., 2017; Porat et al., 2018). Fresh produce constitutes the biggest amount of FLW, reaching $\approx 45 \%$ by weight (Lipinsky et al., 2013). Postharvest losses constitute a considerable portion of the FLW in fresh produce (Beretta et al., 2013; Porat et al., 2018) and they are related to the rate of biological deterioration of the commodity. Fresh fruits and vegetables naturally deteriorate after harvest, and the rate of deterioration is affected by a variety of factors, including respiration, ethylene production and action, compositional changes, water loss, physiological disorders, and pathological breakdown (Kader, 2013). Produce that is subjected to nonoptimum storage temperature and humidity, mechanical damage, and improper packaging demonstrates increased rate of deterioration, which can lead to rapid quality loss (Prusky, 2011). Quality loss can result in disposal of the commodity or reduce its consumer acceptability (Shewfelt et al., 2014), which is one of the main drivers of postharvest food waste in fresh produce (Baldwin, 2002).

MAP is a postharvest intervention that has been successfully implemented for reducing postharvest losses by extending the shelf life and maintaining the quality of a variety of fruits and vegetables (Domínguez et al., 2016; Kader et al., 1989; Mampholo et al., 2015; Zhang et al., 2006). MAP mechanism involves reducing the $\mathrm{O}_{2}$ and increasing the $\mathrm{CO}_{2}$ levels in the atmosphere surrounding the product, which results in reducing its respiration rate and metabolic activity (Kader et al., 1989). The two main types of MAP are active and passive modification of the atmosphere (Zagory and Kader, 1988). In active MAP, the desired atmosphere is established rapidly by flushing the desirable gas mixture in the package (Ghidelli and PérezGago, 2018). In passive MAP, the desired atmosphere is established after a "lag" period, as a result of the synergistic effect of the package film permeability and the respiration rate of the commodity (Charles et al., 2008; Lange, 2000). Active MAP offers the ability to quickly and specifically alter the atmosphere inside the package, and therefore has an immediate impact on the packaged product (Kader and Watkins, 2000), and thus is more effective compared with passive MAP (Gil, 2016). However, it is an expensive technique that requires a high investment in equipment and gases (Rodriguez-Aguilera and Oliveira, 2009). Passive MAP does not require such investment, which makes it an intervention more suitable for smaller operations like small-acreage farmers. Successful implementation of MAP is closely related to the package, the commodity, and the storage environment. Factors affecting MAP include product respiration rate, ethylene production and sensitivity, storage temperature, and tolerance to low $\mathrm{O}_{2}$ and high $\mathrm{CO}_{2}$ levels (Zagory and Kader, 1988). Particularly for passive MAP, a crucial factor affecting its efficacy is the oxygen transmission rate 
(OTR) of the packing film due to its central role in atmosphere establishment (Lange, 2000).

Spinach (Spinacia oleracea) is a cold weather crop rich in micronutrients like folate and carotenoids and also has high antioxidant capacity (Bunea et al., 2008; Pandjaitan et al., 2005). In 2016, the United States was the second largest spinach producer in the world (FAO, 2019). Spinach production in the United States has been steadily increasing, mainly due to a rise in consumer demand driven by increased consumer health awareness (Morelock and Correll, 2008). It is a highly perishable crop (Kader, 2002) and its optimum storage conditions are $0{ }^{\circ} \mathrm{C}$ and $95 \%$ to $98 \%$ relative humidity (RH) (Suslow and Cantwell, 1999). Spinach has been reported to benefit from a MAP with $1 \%$ to $3 \% \mathrm{O}_{2}$ and $8 \%$ to $10 \% \mathrm{CO}_{2}$ when stored at $0{ }^{\circ} \mathrm{C}$ (Suslow and Cantwell, 1999). Spinach stored in (non-MAP) perforated bags at 16 or $20^{\circ} \mathrm{C}$ had a shelf life of $4 \mathrm{~d}$ for both temperatures, whereas at $12{ }^{\circ} \mathrm{C}$ the shelf life was $6 \mathrm{~d}$, and at $1{ }^{\circ} \mathrm{C}$ the shelf life was more than $16 \mathrm{~d}$ (Kou et al., 2014).

Spinach is a crop that is particularly popular among small-acreage growers in the central United States, particularly in the Great Plains area (Knewtson et al., 2010). One of the main challenges that smallacreage growers are facing in this region is access to cooling (Chiebao et al., 2018; Greater Kansas City Food Hub Working Group, 2015). MAP could be a solution for these growers, but it can only have a supplemental effect to temperature management (Kader et al., 1989). Adequate temperature management is the most important and effective tool for shelf life extension and quality maintenance of fresh produce (Kader, 2013; Prusky, 2011). Moreover, MAP is typically designed for optimum storage temperature and when used at other temperatures it can have adverse effects on the packaged product (Brecht et al., 2003). An increase in storage temperature may result in a damaging atmosphere for the packaged product due to $\mathrm{O}_{2}$ depletion and $\mathrm{CO}_{2}$ accumulation, because the product respiration increases but the packag-

Received for publication 18 Nov. 2019. Accepted for publication 30 Dec. 2019.

Published online 3 February 2020.

Submitted as a portion of a thesis in fulfilling a degree requirement.

We thank Paul Andersen, Cassidy Fleck, Tricia Jenkins, Joseph Rundquist, Kelly Gude, Helena Stanley, and the Olathe Horticulture Research and Extension Center for assistance with this project. We also thank C.B. Rajashekar for his valuable advice during this project.

This work was supported by the US Department of Agriculture-National Institute of Food and Agriculture, Agriculture and Food Research Initiative Food Security Grant 11451860.

E.D.P. is the corresponding author. E-mail: epliakoni@ ksu.edu.

This is an open access article distributed under the CC BY-NC-ND license (https://creativecommons.org/ licenses/by-nc-nd/4.0/). ing film gas permeability does not respond equivalently (Exama et al., 1993). The $\mathrm{O}_{2}$ and $\mathrm{CO}_{2}$ tolerance limits vary between commodities (Kader et al., 1989; Sandhya, 2010). Out of tolerance exposure of a commodity will commonly result in off-odor and off-flavor development due to anaerobiosis along with discoloration (Beaudry, 2000; Watkins, 2000). Furthermore, the increase in temperature itself accelerates the deterioration rate of the packaged produce (Kader, 2002), which in combination with the unfavorable atmosphere can rapidly diminish the product quality.

Although MAP is not a substitute for proper temperature management (Lange, 2000), it may have the potential to benefit stored spinach when the cooling capabilities are limited and could be a prospective solution for reducing postharvest spinach losses for those growers who lack proper cooling and storage facilities. A beneficial effect of MAP for produce that is stored in nonoptimum temperatures has been reported for a variety of crops (D'Aquino et al., 2016; Fonseca et al., 2005; Løkke et al., 2012; Murmu and Mishra, 2017), including spinach (Garrido et al., 2016; Medina et al., 2012; Mudau et al., 2018). The main challenge for applying passive MAP in nonoptimum storage temperatures is finding a film with appropriate OTR that can match the respiration rate of the stored product (Lange, 2000) and create a beneficial atmosphere for the product. BreatheWay (Curation Foods, Santa Maria, CA) membrane technology is an innovative approach for creating a beneficial passive MAP in nonoptimum temperatures (Clarke, 2011; Wilson et al., 2019). This membrane uses side chain crystalline polymers spread on a microporous substrate (Clarke, 2011). This membrane has an OTR and carbon dioxide transmission rate $\approx 1000$ times greater than standard 2-mil polypropylene (PP) film (Clarke, 2011), and can further adjust its permeability when exposed to increased temperature (Lange, 2000; Wilson et al., 2019). This specific property constitutes a mechanism by which the BreatheWay membrane is able to be suitable for passive MAP designed for both optimum and nonoptimum temperatures. The BreatheWay technology has been shown to be successful in maintaining the quality of broccoli (Clarke, 2011) and ackee fruit (Emanuel et al., 2018), thus it could be a solution for creating a beneficial passive MAP for spinach stored in nonoptimum temperatures.

The overall objective of this work was to study the potential benefits of passive MAP, using the BreatheWay technology, on the postharvest losses of spinach when stored at nonoptimum temperatures. More specifically, we evaluated the effect of passive MAP when spinach was stored at nonoptimum temperature on its storage life, and its physical, organoleptic, and nutritional quality.

\section{Materials and Methods}

Plant material. Spinach (Spinacia oleracea $\mathrm{cv}$. Corvair) was grown in an open field during the spring of 2018, at the Kansas State University Olathe Horticulture Research and Extension Center, located in Olathe, KS (lat. $38.884347^{\circ} \mathrm{N}$, long. $\left.94.993426^{\circ} \mathrm{W}\right)$. Mature and defect-free spinach leaves were harvested during May in 2018, and immediately transferred, using insulated coolers, to the postharvest physiology laboratory at the Kansas State Olathe campus. In the laboratory, the spinach was washed three times in ice-cold tap water and sorted a second time to remove defective leaves. Next, the spinach was centrifuged using a 5-gallon salad spinner (Chef Master 90005; Mr. Bar-B-Q Products LLC, Melville, NY) for removing excess water before packaging.

Packaging and storage conditions. The modified atmosphere (MA) was established passively using a microporous membrane $\left(\mathrm{OTR} \approx 5 \times 10^{6} \mathrm{cc} / \mathrm{m}^{2} / \mathrm{d}\right)$ with semipermeable polymer coating (BreatheWay) attached over a 12.7-mm diameter hole in a $\mathrm{PP} /$ polyethylene (PE) laminate bag $(30 \mathrm{~cm}$ length $\times 30 \mathrm{~cm}$ width). The membrane was temperature specific and was developed exclusively for this spinach variety for storage at 13 and $21{ }^{\circ} \mathrm{C}$, using respiration measurements of this variety from previous trials (data not shown). These temperatures were selected to reflect the storage temperatures used by local growers in the central United States. Small-acreage growers use $13{ }^{\circ} \mathrm{C}$ for commingling chilling sensitive and nonsensitive crops, and when there is no access to refrigeration, they use air conditioned cooled rooms at $21^{\circ} \mathrm{C}$ (C.L. Rivard, personal communication). The target atmosphere was $3 \%$ to $6 \% \mathrm{O}_{2}$ and $6 \%$ to $12 \% \mathrm{CO}_{2}$ for both temperatures. Approximately $320 \mathrm{~g}$ of spinach was weighed (Sartorius AG, Göttingen, Germany) and placed into the MAP bags. Consequently, the bags were heat-sealed using a tabletop impulse heat-sealer (ULINE, Pleasant Prairie, WI). For the control treatment, $\approx 320 \mathrm{~g}$ of spinach was weighed and placed in plastic produce bags. The produce bags were not sealed but they were folded to limit water loss, which is a common practice among local growers. The MAP and control bags were stored in environmental chambers (ThermoFisher Scientific Inc., Asheville, NC), in two different temperature conditions: at $13{ }^{\circ} \mathrm{C}$ with $95 \% \mathrm{RH}$ and $21{ }^{\circ} \mathrm{C}$ with $95 \% \mathrm{RH}$. The analyses were performed destructively on days $0,3,5,7$, and 9 for $13{ }^{\circ} \mathrm{C}$ and on days $0,1,2,3,4$, and 5 for $21^{\circ} \mathrm{C}$. For both treatments, there were three replicates per day of analysis, prepared on day 0 and then randomly assigned for each analysis day. The experiment was conducted twice for each temperature using spinach harvested from the same plot.

Headspace composition. The headspace composition in the MAP and produce bags was determined by measuring $\mathrm{O}_{2}, \mathrm{CO}_{2}$, and ethylene concentrations. A portable gas analyzer (Bridge Analyzer, Bedford Heights, $\mathrm{OH}$ ) was used to measure the $\mathrm{O}_{2}$ and $\mathrm{CO}_{2}$ concentration. Ethylene was measured by extracting a sample of $1 \mathrm{~mL}$ from the headspace of each bag using a syringe. The sample was injected onto a gas chromatograph (SRI Instruments, Torrance, CA) fitted with a 
flame ionization detector with $10 \mathrm{ppb}$ limit of detection and equipped with a $6-\mathrm{ft}$ HAYESEP-D stainless steel column (100/ 120 mesh). The injector, column, and detector temperatures were set at $125^{\circ} \mathrm{C}$, respectively, and helium was used as the carrier gas at a flow rate of $20 \mathrm{~mL} \cdot \mathrm{min}^{-1}$.

Physical quality. The physical quality of the spinach during storage life was evaluated by measuring overall quality, water loss, leaf surface color, leaf tenderness, electrolyte leakage, chlorophyll fluorescence, and chlorophyll content.

Overall quality. Spinach overall quality was measured similar to Medina et al. (2012). For each treatment, 20 leaves per replicate were evaluated by two trained analysts, taking into account freshness, appearance, color, uniformity, and off-odor presence and rated from $9=$ "excellent" to $1=$ "extremely poor"; the limit of product marketability was considered $5=$ "Fair." When $30 \%$ of the treatment scored below 5 , the treatment was ended, indicating the end of storage life.

Water loss. The water loss of the stored spinach leaves was evaluated similar to Agüero et al. (2008). The spinach packaged in each treatment was weighed on day $0\left(\mathrm{~W}_{0}\right)$ of each experiment and on each analysis day $\left(\mathrm{W}_{\mathrm{A}}\right)$. The water loss of each treatment was calculated using the following formula: Water Loss $(\mathrm{WL} \%)=\left(1-\mathrm{W}_{0} / \mathrm{W}_{\mathrm{A}}\right) \times 100$.

Leaf tenderness. The tenderness of the spinach leaves was measured using a texture analyzer TA-58, TA.XT.plus (Texture Technologies Corp., Scarsdale, NY), equipped with a 5-blade TA-91 Kramer Shear Cell (Texture Technologies). The return distance of the probe was set at $35 \mathrm{~mm}$, the test speed at $1.7 \mathrm{~mm} / \mathrm{s}$, and the return speed was set at $10 \mathrm{~mm} / \mathrm{s}$. For each measurement, the midribs of 10 leaves per replication were removed and the leaves were stacked and weighed. The maximum force required to cut through the spinach leaf stack was measured similar to Gomes et al. (2008) and Prakash et al. (2000). Leaf tenderness was calculated as the maximum force in Newtons per gram $(\mathrm{N} / \mathrm{g})$.

Leaf surface color. The color of five leaves per replicate for each treatment was measured using an A5 Chroma-Meter Minolta CR-400 (Minolta Co. Ltd., Osaka, Japan). The color measurements were taken on the upper part of the leaf at two opposite points to the central leaf axis. Color results are expressed in the CIE $\mathrm{L}^{*} \mathrm{a}^{*} \mathrm{~b}^{*}$ color space, where $\mathrm{L}^{*}$ is lightness and $\mathrm{h}^{\circ}$ is hue angle,

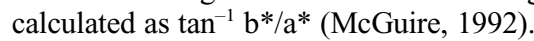

Chlorophyll content. The extraction and quantification of the spinach leaf chlorophyll content was performed according to the method developed by Wellburn (1994). On the day of the physical quality analysis, samples of $0.3 \mathrm{~g}$ of spinach leaf fresh tissue from each replicate were rapidly frozen using liquid nitrogen and stored at $-20{ }^{\circ} \mathrm{C}$ in the dark until the extraction day. Chlorophyll was extracted by homogenizing the plant tissue in $10 \mathrm{~mL}$ of pure methanol using a benchtop homogenizer (POLYTRON PT 1600 E; Kinematica AG, Luzern, Switzerland) and subsequently incubated at $4{ }^{\circ} \mathrm{C}$ in darkness for $24 \mathrm{~h}$. After the incubation period, the samples were measured with a 96-well microplate reader spectrophotometer (Synergy H1; BioTek Instruments, Inc., Winooski, VT) at $653 \mathrm{~nm}$ [chlorophyll b (Chl b)] and $666 \mathrm{~nm}$ [chlorophyll a (Chl a)]. The total chlorophyll content was calculated using the following equations: Total chlorophyll content $=\mathrm{Chl} \mathrm{a}+$ Chl b, and Chl a: [15.65 $\times(\mathrm{A} 666)-(7.34 \times$ (A653)]; Chl b: [27.05 × (A653) - (11.21 $\times$ (A666)]. The total chlorophyll content was expressed as $\mathrm{mg} / 100 \mathrm{~g}$ fresh weight (FW).

Electrolyte leakage. The electrolyte leakage of the stored spinach was measured by modifying the method described by Bajji et al. (2002). For each replicate, 20 leaf disks obtained from 10 leaves (diameter $10 \mathrm{~mm}$ ) were placed in $20 \mathrm{~mL}$ of deionized water in a $50-\mathrm{mL}$ tube and the electrolyte leakage was measured immediately (this value is denoted as $\mathrm{EC}_{0}$ ) using a conductivity meter (OHAUS Corporation, Parsippany, NJ). Thereafter the tubes were incubated at $21{ }^{\circ} \mathrm{C}$ on a platform shaker (ThermoFisher Scientific, Waltham, $\mathrm{MA})$ at $30 \mathrm{rpm}$ for $2 \mathrm{~h}$ and after that period the measurement was repeated (this value is denoted as $\mathrm{EC}_{1}$ ). Subsequently, the samples in tubes were stored at $-20{ }^{\circ} \mathrm{C}$ until the final measurement day. Electrolyte leakage measured after thawing (this value is denoted as $\left.\mathrm{EC}_{\max }\right)$ is assumed to be $100 \%$ for the given sample. Before the measurement of ECmax, the tubes were incubated on a platform shaker at $80 \mathrm{rpm}$ until the samples reached $21^{\circ} \mathrm{C}$. The electrolyte leakage was expressed as a percentage, calculated using the following formula: Electrolyte leakage $(\mathrm{EL} \%)=\left[\left(\mathrm{EC}_{1}-\right.\right.$ $\left.\left.\mathrm{EC}_{0}\right) / \mathrm{EC}_{\max }-\mathrm{EC}_{0}\right] \times 100$

Chlorophyll fluorescence. Chlorophyll fluorescence was determined using a pulse modulated OS30p + chlorophyll fluorometer (Opti-Sciences Inc., Hudson, NH). Three leaves per replicate were used for this measurement. Dark adaptation was accomplished, as proposed by Maxwell and Johnson (2000), using FL-DC clips (OptiSciences Inc.) attached on the leaves for $30 \mathrm{~min}$ before the measurement. Minimal fluorescence (Fo) and maximal fluorescence $(\mathrm{Fm})$ were analyzed, and the ratio of variable fluorescence $(\mathrm{Fv})$ to maximal fluorescence $(\mathrm{Fm})(\mathrm{Fv} / \mathrm{Fm})$ was calculated by the instrument.

Nutritional quality. The nutritional quality of the stored spinach was evaluated by measuring total phenolic content, antioxidant capacity, and vitamin $\mathrm{C}$ content. On the days of the physical quality analyses, spinach leaves were immediately frozen using liquid nitrogen and thereafter stored at $-20{ }^{\circ} \mathrm{C}$ for the nutritional quality analyses. The frozen spinach samples were freeze-dried (Harvest Right Freeze Drier, North Salt Lake, UT) and then pulverized using a pestle and mortar. Each time the water content was calculated by weighing each sample before and after freeze drying. The extraction method used for determining antioxidant capacity and total phenolic content was described by Huang et al. (2002); $0.2 \mathrm{~g}$ of spinach powder was homogenized in centrifuge tubes with $20 \mathrm{~mL}$ of acetone/water (1/1) solution. The mixture was shaken at $80 \mathrm{rpm}$ for $1 \mathrm{~h}$ using a platform shaker (ThermoFisher Scientific, Waltham, MA) and then centrifuged (JA-17; Beckman Coulter, Palo Alto, CA) for $20 \mathrm{~min}$ at $4{ }^{\circ} \mathrm{C}$ and $17,600 g_{\mathrm{n}}$. The supernatant was used for the antioxidant capacity and total phenolic content analyses.

Antioxidant capacity. The antioxidant capacity of the samples was determined by measuring the ferric reducing ability of plasma (FRAP) and the oxygen radical absorbance capacity (ORAC). The FRAP measurement was performed following the method described by Benzie and Strain (1996). Absorbance at $593 \mathrm{~nm}$ was measured against a trolox positive control using a spectrophotometer equipped with a 96-well microplate reader (Synergy H1; BioTek Instruments, Inc.). FRAP was expressed as $\mu \mathrm{M}$ trolox equivalent in $100 \mathrm{~g} \mathrm{FW}$ basis ( $\mu \mathrm{M}$ TE/ $100 \mathrm{~g} \mathrm{FW}$ ). The ORAC measurement was performed according to the method described by Cao et al. (1993) and modified by Ou et al. (2001) and Prior et al. (2003) using a spectrophotometer equipped with a 96-well microplate reader (Synergy H1). The antioxidant activity was correlated with the oxidative damage to the fluorescent probe against a trolox positive control. ORAC was expressed as $\mu \mathrm{M} \mathrm{TE} / 100 \mathrm{~g} \mathrm{FW}$.

Total phenolic content. The total phenolic content of the spinach leaves was determined using the method developed by Singleton and Rossi (1965). Using a spectrophotometer equipped with a 96-well microplate reader (Synergy $\mathrm{H} 1$ ), the extracted samples were measured at $750 \mathrm{~nm}$ absorbance. Total phenolic content was expressed as mg gallic acid equivalents on a $100 \mathrm{~g}$ FW basis (mg GAE/100 $\mathrm{g} \mathrm{FW}$ ).

Vitamin $C$ content. On the days of the physical quality analyses, following the method of Klimczak and GliszczynskaWiglo (2015), $2 \mathrm{~g}$ of fresh spinach leaves from each replication were homogenized with $20 \mathrm{~mL}$ of an acid solution $(6 \%$ metaphosphoric acid/2N glacial acetic acid) using a homogenizer (POLYTRON). Subsequently, the samples were stored at $-20{ }^{\circ} \mathrm{C}$ and analyzed later using ultra performance liquid chromatography (UPLC). On the days of analysis, after thawing, the samples were centrifuged at $8500 g_{\mathrm{n}}$ for $10 \mathrm{~min}$ (JA-17; Beckman). The supernatant was further diluted with the acid solution and then filtered with a $0.2-\mu \mathrm{m}$ nylon and glass microfiber filter Whatman syringe filter (Whatman Inc., Clifton, NJ). An Acquity photodiode array detector (PDA) QDa Waters UPLC (Waters Corp., Milford, MA) equipped with an Acquity BEH C18 column (Waters Corp.) was used for the analysis. The injection volume was $5 \mu \mathrm{L}$ and the flow rate was set at $0.2 \mathrm{~mL} /$ min. The mobile phase was composed of $5 \mathrm{~mm}$ potassium phosphate monobasic $\left(\mathrm{KH}_{2}\right.$ $\left.\mathrm{PO}_{4}\right), \mathrm{pH} 2.65$, with $0.1 \%$ of formic acid (solution A) and methanol with $0.1 \%$ of formic acid (solution B). The linear gradient of the mobile phase was programmed as follows: $5 \%$ to $15 \% \mathrm{~B}$ for $1 \mathrm{~min}$, followed 
by $15 \%$ to $35 \% \mathrm{~B}$ for $1 \mathrm{~min}$ and return to initial conditions in $4 \mathrm{~min}$. A PDA was used for measuring vitamin $C$ at $245 \mathrm{~nm}$. The quantification of vitamin $\mathrm{C}$ was performed using a five-point standard curve $(2.5 \mu \mathrm{g} /$ $\mathrm{mL}-50 \mu \mathrm{g} / \mathrm{mL}$ ) with purified ascorbic acid (assay percentage range $\geq 99.0 \%$; Fisher Scientific, Hampton, NH) as a standard. The vitamin $\mathrm{C}$ content was expressed as $\mathrm{mg}$ ascorbic acid on a $100 \mathrm{~g} \mathrm{FW}$ basis (mg AA/ $100 \mathrm{~g} \mathrm{FW}$ ). In the cases that the vitamin $\mathrm{C}$ content was below the quantification limit $(0.024 \mu \mathrm{g} / \mathrm{mL})$, the half value of the quantification limit was used in the subsequent statistical analysis.

Statistical analysis. This study implemented a generalized randomized block design with trial being the blocking factor at the two temperature levels and a two-way factorial treatment. Each quality parameter was analyzed separately for each temperature under the linear mixed model. Fixed effects of the linear mixed model were the trial and the treatment group defined by the factorial treatment structure. Residual variance was taken as heterogeneous with respect to storage status (i.e., MAP vs. Control treatment). The effect of the MAP treatment was evaluated against the Control treatment within a given storage day based on a two-sided test for non-zero difference. Least square means (LSMean) and their standard errors are reported for each treatment group. The statistical analysis was executed using the Statistical Analysis Software (version 9.4; SAS Institute, Cary, NC) and using the PROC
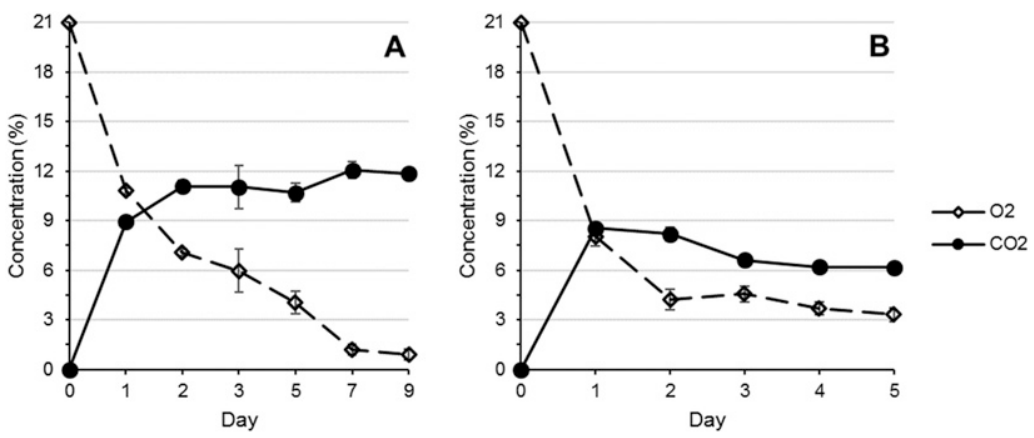

Fig. 1. Headspace composition of spinach packaged in passive modified atmosphere packaging and stored at $13{ }^{\circ} \mathrm{C}(\mathbf{A})$ or $21{ }^{\circ} \mathrm{C}(\mathbf{B})$ for 9 and $5 \mathrm{~d}$ respectively. Each value represents the mean $( \pm \mathrm{SE})$ of measurements obtained from two trials with the same experimental conditions with three replicates in each trial.
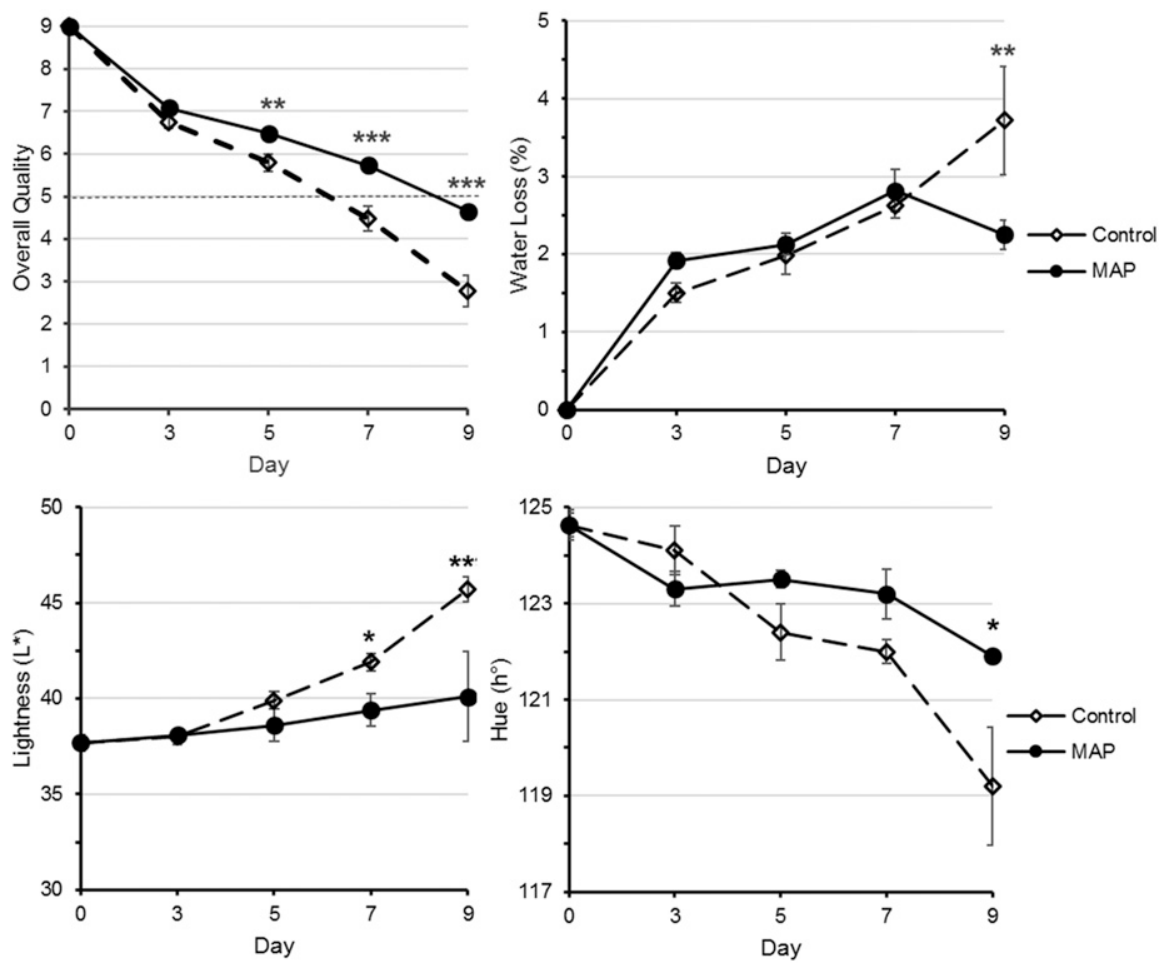

Fig. 2. Overall quality, water loss, lightness, and hue angle of spinach packaged in produce bags (Control) or passive modified atmosphere packaging (MAP) and stored at $13{ }^{\circ} \mathrm{C}$ for $9 \mathrm{~d}$. Each value represents the mean $( \pm \mathrm{SE})$ of measurements obtained from two trials with the same experimental conditions with three replicates in each trial.
MIXED with Kenward-Roger set as the denominator df methods option (DDFM=KR).

\section{Results}

Quality of spinach during storage at $13{ }^{\circ} \mathrm{C}$. The spinach stored in passive MAP reached a headspace equilibrium atmosphere of $\approx 6 \% \mathrm{O}_{2}$ plus $11 \% \mathrm{CO}_{2}$ after $2 \mathrm{~d}$ of storage at $13{ }^{\circ} \mathrm{C}$ (Fig. 1A). The $\mathrm{O}_{2}$ concentration in the MAP started declining again from day 5 on, reaching $\approx 0.5 \%$ on day 7 and remained at this level until day 9 , whereas the $\mathrm{CO}_{2}$ concentration increased to $12 \%$ on day 7 and remained steady until the end of the storage life (Fig. 1A). The headspace in the produce bag was measured at the same time intervals with the MAP headspace and it was found to be the same as ambient air $\left(\approx 20.95 \% \mathrm{O}_{2}\right.$ and $0.04 \% \mathrm{CO}_{2}$ ). There was no ethylene detected in either the MAP or produce (control) bags during the storage life.

Overall quality. The spinach stored in MAP at $13{ }^{\circ} \mathrm{C}$ maintained significantly higher overall quality compared with the spinach stored in produce bags from day 5 of storage until the end of shelf life on day 9 (Fig. 2). The spinach stored in the produce bags was unmarketable after $7 \mathrm{~d}$ at $13{ }^{\circ} \mathrm{C}$, whereas the spinach stored in MAP was unmarketable after $9 \mathrm{~d}$ (Fig. 2). There was no difference in water loss between the two treatments for the first $7 \mathrm{~d}$ of storage, but by day 9 the spinach in MAP had lost $1.5 \%$ less weight $(P<0.01)$ than the spinach in produce bags (Fig. 2). There was no difference in leaf tenderness between the two treatments (Table 1). The leaf color did not differ between the two treatments until after $5 \mathrm{~d}$ of storage at $13{ }^{\circ} \mathrm{C}$ (Fig. 2). However, the spinach in MAP was darker than the spinach in the produce bags on days 7 and $9(P<0.05$ and $P<0.001$, respectively) (Fig. 2). On day 9 , the spinach in MAP maintained higher hue values compared with the spinach in the produce bags $(P<0.05)$ (Fig. 2$)$. The chlorophyll content of the spinach in MAP was $28 \%$ higher than the spinach in the produce bags $(P<0.001)$ (Fig. 3). The spinach packed in MAP had 5\% and 6\% less electrolyte leakage on day $7(P<0.05)$ and day $9(P<$ $0.01)$, respectively, compared with spinach stored in the produce bags (Fig. 3). The MAP-packaged spinach also had lower Fv/ Fm values $(P<0.05)$ compared with spinach in produce bags on days 5 and 7 ; however, there was no difference in chlorophyll fluorescence on the last day of the storage life (Fig. 3). When examining the nutritional quality parameters, ORAC, FRAP, total phenolic content, and vitamin $\mathrm{C}$, there were no significant differences between the two treatments (Table 1).

Quality of spinach during storage at $21{ }^{\circ} C$. The spinach stored in the passive MAP reached an equilibrium atmosphere of $\approx 4 \% \mathrm{O}_{2}$ plus $8 \% \mathrm{CO}_{2}$ after $2 \mathrm{~d}$ of storage at $21{ }^{\circ} \mathrm{C}$ (Fig. 1B). The $\mathrm{CO}_{2}$ concentration in the MAP started declining again from day 3 on, reaching $\approx 6 \%$ on day 5 , whereas the $\mathrm{O}_{2}$ declined slightly to $3 \%$ (Fig. 1B). The 
Table 1. $P$ values reflecting the effects of storage day, treatment, and their interactions on overall quality, water loss, leaf tenderness, leaf color, chlorophyll content, electrolyte leakage, chlorophyll fluorescence, total phenolic content, antioxidant capacity, and vitamin $\mathrm{C}$ content of spinach stored in modified atmosphere or produce bags at $13^{\circ} \mathrm{C}$ for $9 \mathrm{~d}$.

\begin{tabular}{|c|c|c|c|}
\hline \multirow[b]{2}{*}{ Parameter $^{z y}$} & \multicolumn{3}{|c|}{$P$ value } \\
\hline & Storage day & Treatment & Storage day $\times$ Treatment \\
\hline Overall quality & $<0.0001$ & $<0.0001$ & $<0.0001$ \\
\hline Water loss & $<0.001$ & $\mathrm{NS}^{\mathrm{x}}$ & $<0.05$ \\
\hline Leaf tenderness & $<0.0001$ & NS & NS \\
\hline Color-lightness & $<0.0001$ & $<0.001$ & $<0.05$ \\
\hline Color-hue & $<0.0001$ & $<0.05$ & $<0.05$ \\
\hline Chlorophyll content & NS & NS & NS \\
\hline Electrolyte leakage & $<0.05$ & $<0.05$ & NS \\
\hline Chlorophyll fluorescence & $<0.0001$ & $<0.01$ & NS \\
\hline Oxygen radical absorbance capacity & NS & NS & NS \\
\hline Ferric reducing ability of plasma & $<0.0001$ & NS & NS \\
\hline Total phenolic content & NS & NS & NS \\
\hline Vitamin $\mathrm{C}$ & $<0.0001$ & NS & NS \\
\hline
\end{tabular}

${ }^{\mathrm{z}} \mathrm{A}$ linear mixed model was used to test which factors and interactions between factors had significant effects on the examined quality parameters $(\alpha=0.05)$. ${ }^{\mathrm{y}}$ The analysis included two trials performed with the same experimental conditions.

$\mathrm{x}_{\mathrm{NS}}=$ nonsignificant.
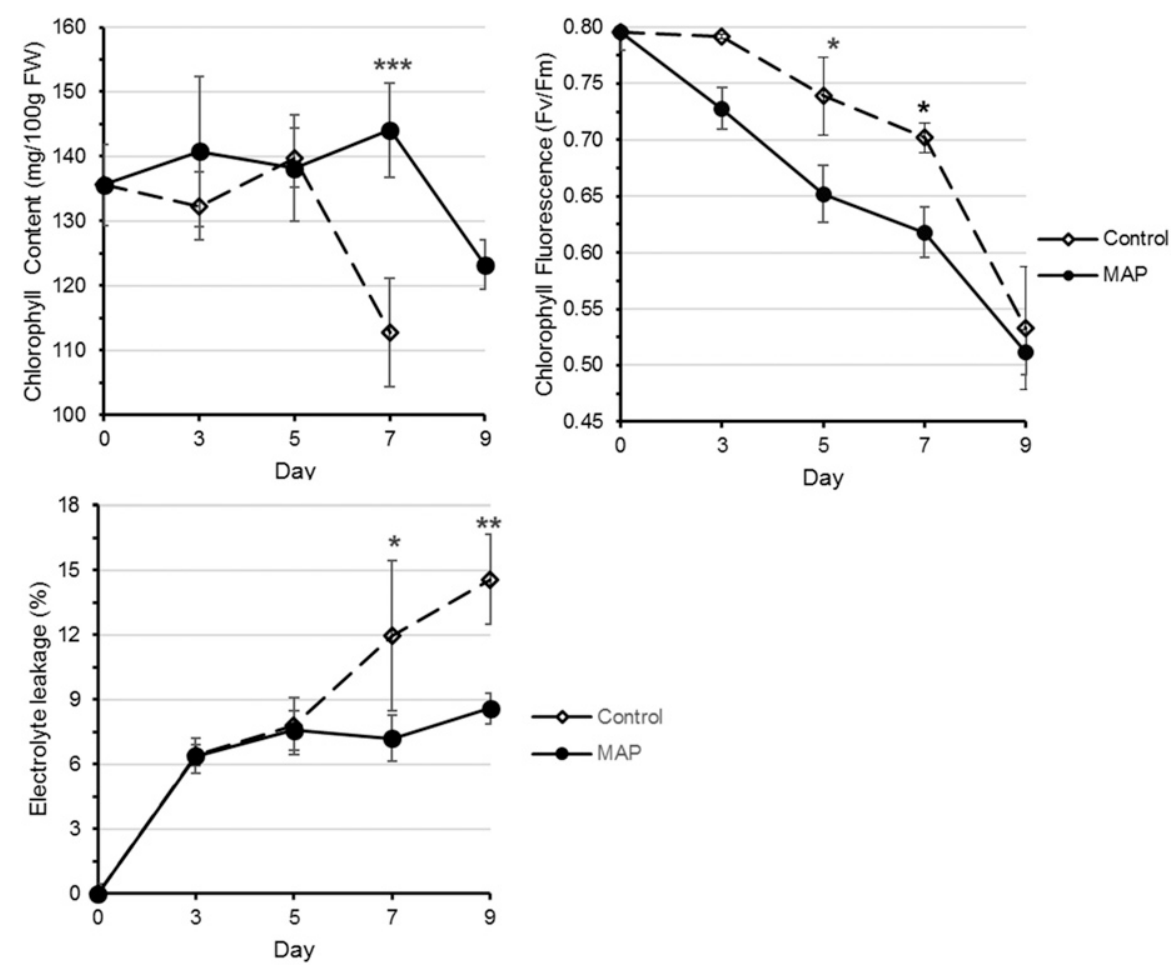

Fig. 3. Chlorophyll content, chlorophyll fluorescence and electrolyte leakage of spinach leaves packaged in produce bags (Control) or passive modified atmosphere packaging (MAP) and stored at $13{ }^{\circ} \mathrm{C}$ for $9 \mathrm{~d}$. Each value represents the mean $( \pm \mathrm{SE})$ of measurements obtained from two trials with the same experimental conditions with three replicates in each trial. $\mathrm{Fv} / \mathrm{Fm}$, ratio of variable fluorescence to maximal fluorescence; $\mathrm{FW}$, fresh weight.

headspace in the produce was measured at the same time intervals with the MAP headspace and it was found to be same as the ambient air (data not shown). There was no ethylene detected in either the MAP or produce bags during the storage life.

The spinach stored in MAP maintained significantly higher overall quality compared with the spinach stored in produce bags from day 2 of storage until the end of storage life on day 5 (Fig. 4). The spinach stored in the produce bags was unmarketable after $4 \mathrm{~d}$ of storage at $21^{\circ} \mathrm{C}$. There was no difference in water loss between the two treatments for the first $3 \mathrm{~d}$ of storage, but the spinach in MAP had lost $1.4 \%(P<0.01)$ and $1.0 \%(P<0.05)$ less water than the spinach in produce bags on days 4 and 5, respectively (Fig. 4). There was no difference in leaf tenderness between the two treatments (Table 2). The leaf color did not differ between the two treatments after $3 \mathrm{~d}$ of storage at $21^{\circ} \mathrm{C}$ (Fig. 4). On days 4 and 5, the spinach in MAP had darker leaves compared with the spinach in produce bags $(P<0.05)$ (Fig. 4). On day 5 of storage, the spinach in MAP had higher hue values, indicating more green vs. yellow color compared with the spinach in produce bags $(P<$ 0.05 ) (Fig. 4). However, there was no difference in the chlorophyll content between the two treatments (Table 2). The spinach packed in MAP demonstrated $1.7 \%$ higher electrolyte leakage on day $3(P<0.05)$ compared with spinach stored in produce bags, but for the rest of the storage life there was no difference in electrolyte leakage between the two treatments (Fig. 5). The MAPpackaged spinach also had higher $\mathrm{Fv} / \mathrm{Fm}$ values $(P<0.001)$ than the spinach in produce bags on day 5 (Fig. 5). There were no differences in the nutritional quality between the two treatments as defined by ORAC, FRAP, total phenolic content, and vitamin C (Table 2).

\section{Discussion}

The goal of this work was to study the effect of passive MAP on the postharvest losses of spinach when stored at nonoptimum temperatures, as evaluated by storage life, physical quality, and nutritional quality.

The benefits of MAP applied at optimum storage temperatures have been well documented (Ghidelli and Pérez-Gago, 2018; Sandhya, 2010; Wilson et al., 2019). Temperature control remains the most effective postharvest management technique for reducing the rate of deterioration of fresh fruits and vegetables (Kader, 2013; Prusky, 2011). However, MAP can only provide complementary benefits to temperature control (Kader et al., 1989; Sandhya, 2010). All the metabolic processes and physiological responses in plant tissues are strongly affected by their surrounding temperature (Kader and Saltveit, 2003; Nunes and Emond, 2002). Such processes and responses include respiration, ethylene production, and sensitivity to ethylene, water loss, compositional changes, and physiological breakdown (Prusky, 2011). However, maintaining the optimum storage temperature is not always feasible, especially in smaller horticultural operations (Cantor and Strochlic, 2009; Harrison et al., 2013). The optimum postharvest temperature for leafy greens is near $0{ }^{\circ} \mathrm{C}$, but there have been MAP designs that have shown benefits at nonoptimum storage temperatures (Fonseca, 2006; Løkke et al., 2012; Mudau et al., 2018). 
The shelf life of shredded kale (Brassica oleracea var. acephala DC.) was extended for $2 \mathrm{~d}$ when stored in MAP vs. air at $20^{\circ} \mathrm{C}$ to simulate retail handling conditions (Fonseca et al., 2005). Wild rocket (Diplotaxis tenuifolia L.) maintained good visual quality after $4 \mathrm{~d}$ of MAP storage at $10{ }^{\circ} \mathrm{C}$ (Løkke et al., 2012), whereas the shelf life of spinach stored in MAP at $20{ }^{\circ} \mathrm{C}$ was extended for $3 \mathrm{~d}$ (Mudau et al., 2018). Our results indicate that passive MAP created using the BreatheWay technology is beneficial to the postharvest quality and storage life of spinach at nonoptimum storage temperatures. The spinach stored in our passive MAP design maintained higher overall quality beginning on day 2 of storage at $21^{\circ} \mathrm{C}$ and day 3 at $13^{\circ} \mathrm{C}$ until the end of the storage period. Consequently, the storage life of spinach stored in passive MAP was extended for $1 \mathrm{~d}$ at $21^{\circ} \mathrm{C}$ and $2 \mathrm{~d}$ at $13{ }^{\circ} \mathrm{C}$.

One of the main challenges in designing a MAP bag for storage at nonoptimum temperatures is coupling the film permeability with the respiration rate of the product to create a noninjurious but also beneficial (to the product) atmosphere (Exama et al., 1993). As reported by Løkke et al. (2012) most of the MAP configurations used for storage of wild rocket at 10 or $20^{\circ} \mathrm{C}$ developed injurious $\mathrm{O}_{2}$
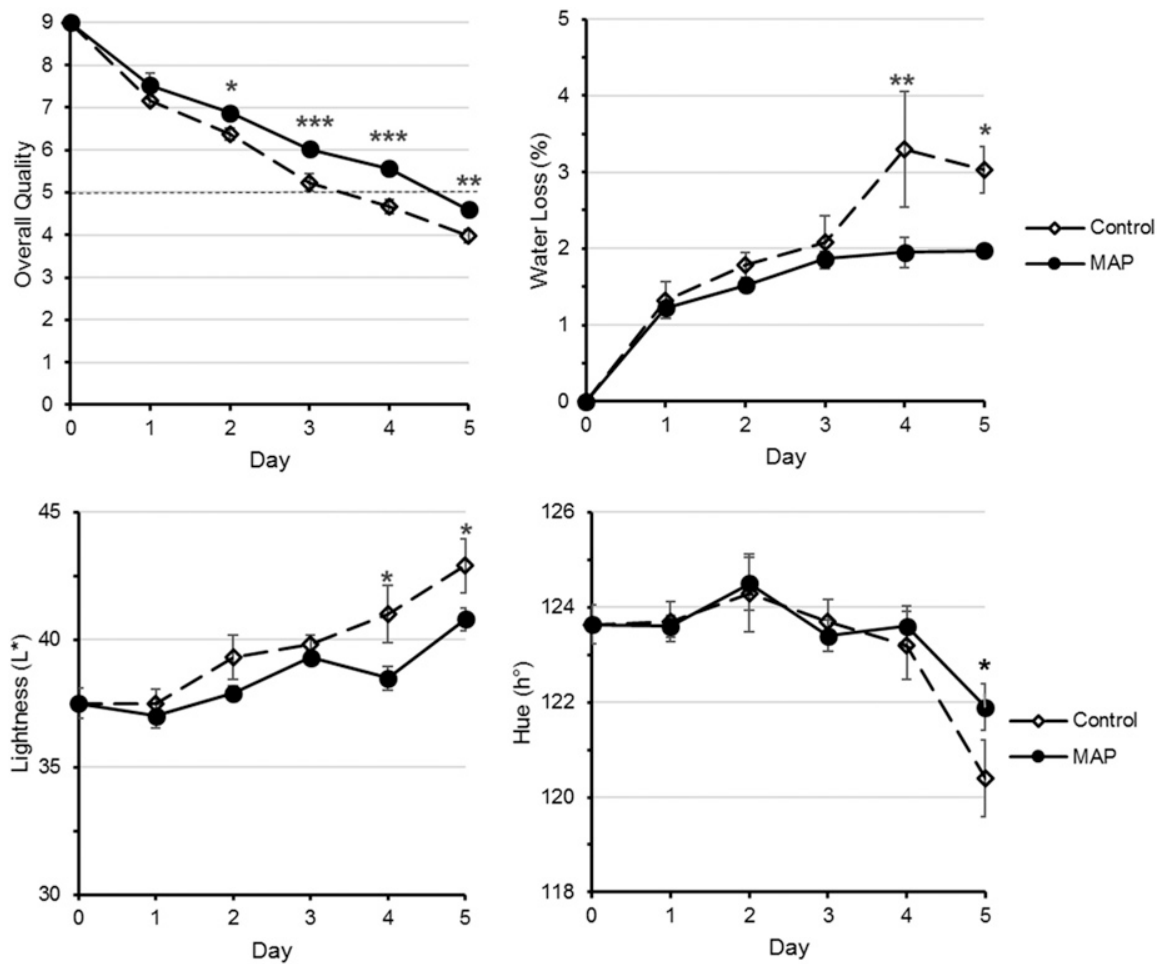

Fig. 4. Overall quality, water loss, lightness, and hue angle of spinach packaged in produce bags (Control) or passive modified atmosphere packaging (MAP) and stored at $21^{\circ} \mathrm{C}$ for $5 \mathrm{~d}$. Each value represents the mean $( \pm \mathrm{SE})$ of measurements obtained from two trials with the same experimental conditions with three replicates in each trial. and $\mathrm{CO}_{2}$ concentrations, which led to anaerobiosis and off-odor development, or they created a noninjurious but not beneficial headspace. Similarly, Rux et al. (2017) reported injurious headspace conditions for rucola (i.e., rocket) stored at $20{ }^{\circ} \mathrm{C}$. Mudau et al. (2018) reported $\mathrm{CO}_{2}$ levels up to $18 \%$ for spinach stored in MAP at $20^{\circ} \mathrm{C}$. Spinach packed in passive MAP created using an ethylene-vinyl alcohol copolymer/polyolephin film and stored at $13{ }^{\circ} \mathrm{C}$ or $28{ }^{\circ} \mathrm{C}$ had $<1 \% \quad \mathrm{O}_{2}$ and $>30 \% \mathrm{CO}_{2}$ after 3 and $1 \mathrm{~d}$, respectively (Park et al., 2006) and packaging spinach in MAP with such headspace led to off-odor development (Tudela et al., 2013). Spinach stored at $7{ }^{\circ} \mathrm{C}$ in passive MA (steady state at $0.5 \% \mathrm{O}_{2}$ and $10 \% \mathrm{CO}_{2}$ ) was of acceptable visual quality after $10 \mathrm{~d}$ but developed off-odors (Garrido et al., 2016). In this specific study, the atmosphere was modified using a PP film that had low OTR compared with other available films (Yaptenco et al., 2007) and, as a result, the atmosphere reached the lower $\mathrm{O}_{2}$ injury threshold for spinach (Beaudry, 2000). Medina et al. (2012) reported results similar to Garrido et al. (2016), with spinach stored at $7{ }^{\circ} \mathrm{C}$ in passive MAP using a PP film resulting in offodor development after $12 \mathrm{~d}$. In our experiments, the atmosphere created using the BreatheWay technology had an equilibrium of $4 \% \mathrm{O}_{2}$ plus $8 \% \mathrm{CO}_{2}$ at $21{ }^{\circ} \mathrm{C}$ and $6 \% \mathrm{O}_{2}$ plus $11 \% \mathrm{CO}_{2}$ at $13{ }^{\circ} \mathrm{C}$. These atmospheres are within the noninjurious $\mathrm{O}_{2}$ (Beaudry, 2000) and $\mathrm{CO}_{2}$ (Cantwell et al., 2010) limits reported for spinach. However, at $13{ }^{\circ} \mathrm{C}$ in this research, the $\mathrm{O}_{2}$ concentration reached $<1 \%$ after $7 \mathrm{~d}$ of storage accompanied by off-odor development. Off-odor development is a major problem in MAP spinach storage, and it is linked to low $\mathrm{O}_{2}$ levels in the packaging (Tudela et al., 2013).

We believe that the $\mathrm{O}_{2}$ reduction during the latter part of the storage period was related to the appearance of decay in the MAP bags, which was the limiting factor at $13{ }^{\circ} \mathrm{C}$, and was caused by water condensation. Most of the polymeric films used in MAP, including PP and PE films, have a low water vapor transmission rate (WVTR) (Tano

Table 2. $P$ values reflecting the effects of storage day, treatment, and their interactions on overall quality, water loss, leaf tenderness, leaf color, chlorophyll content, electrolyte leakage, chlorophyll fluorescence, total phenolic content, antioxidant capacity, and vitamin $\mathrm{C}$ content of spinach stored in modified atmosphere or produce bags at $21^{\circ} \mathrm{C}$ for $5 \mathrm{~d}$.

\begin{tabular}{|c|c|c|c|}
\hline \multirow[b]{2}{*}{ Parameter $^{z y}$} & \multicolumn{3}{|c|}{$P$ value } \\
\hline & Storage day & Treatment & Storage day $\times$ Treatment \\
\hline Water loss & $<0.001$ & $<0.001$ & NS \\
\hline Color-lightness & $<0.0001$ & $<0.01$ & NS \\
\hline Color-hue & $<0.0001$ & NS & NS \\
\hline Chlorophyll content & NS & NS & NS \\
\hline Electrolyte leakage & $<0.01$ & $<0.05$ & NS \\
\hline Ferric reducing ability of plasma & NS & NS & NS \\
\hline Total phenolic content & NS & NS & NS \\
\hline Vitamin $\mathrm{C}$ & $<0.0001$ & NS & NS \\
\hline
\end{tabular}

${ }^{\mathrm{z}} \mathrm{A}$ linear mixed model was used to test which factors and interactions between factors had significant effects on the examined quality parameters $(\alpha=0.05)$.

${ }^{\mathrm{y}}$ The analysis included two trials performed with the same experimental conditions.

${ }^{\mathrm{N}} \mathrm{NS}=$ nonsignificant. 

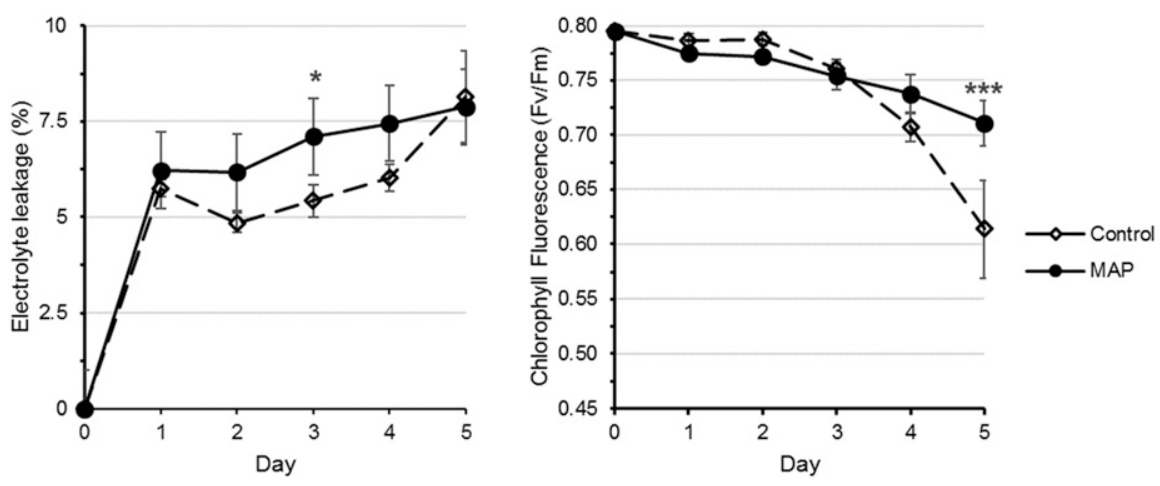

Fig. 5. Electrolyte leakage and chlorophyll fluorescence of spinach leaves packaged in produce bags (Control) or passive modified atmosphere packaging (MAP) and stored at $21^{\circ} \mathrm{C}$ for $5 \mathrm{~d}$. Each value represents the mean $( \pm \mathrm{SE})$ of measurements obtained from two trials with the same experimental conditions with three replicates in each trial. Fv/Fm, ratio of variable fluorescence to maximal fluorescence.

et al., 2007). Consequently, storing produce in MAP at nonoptimum temperatures can create high humidity conditions in the package and condensation development (Brecht et al., 2003; Sandhya, 2010), which may result in decay development (Ben-Yehoshua et al., 1998). This was the case in our experiment for the spinach that was stored at $13{ }^{\circ} \mathrm{C}$. To reduce condensation and potentially improve the effectiveness of the MAP packaging, pairing the BreatheWay membrane with a film with higher WVTR, such as nylon-6/ PE film, should be considered, because that film has the appropriate moisture transport properties for limiting water vapor build up (Lim et al., 1999).

The lower chlorophyll fluorescence values observed in MAP at $13{ }^{\circ} \mathrm{C}$ could probably be explained by the rapid reduction in $\mathrm{O}_{2}$ concentration that we observed on days 5 and 7. Low $\mathrm{Fv} / \mathrm{Fm}$ values are a good indicator of stress in leafy vegetables (Baldassarre et al., 2011), which means the spinach stored in MAP at $13{ }^{\circ} \mathrm{C}$ was likely undergoing physiological stress. However, the spinach stored in MAP at $13{ }^{\circ} \mathrm{C}$ demonstrated significantly lower electrolyte leakage and higher overall quality than the control treatment. In spinach, electrolyte leakage has been correlated with product quality (Kou et al., 2014). This disparity may be related to the fact that plant tissue stress is not always visible and its visual symptoms need a "lag" storage phase to be demonstrated (Baldassarre et al., 2011). Schofield et al. (2005) reported a similar disparity: iceberg lettuce (Lactuca sativa L.) of similar visual quality but different chlorophyll fluorescence differentiated in visual and physical quality during storage in correlation with the chlorophyll fluorescence. The spinach stored in MAP at $21^{\circ} \mathrm{C}$ in our experiments had higher chlorophyll fluorescence than the control treatment on the last day of its storage life, indicating a less stressed plant tissue, and there were no major differences in electrolyte leakage between the two treatments at this temperature.

The quality and shelf life of leafy green vegetables is predominantly determined by fresh appearance and crisp texture and subsequently by the rate of water loss and chlorophyll breakdown occurring in the commodity during storage (Cantwell and Kasmire, 2002). The main challenges in spinach storage at nonoptimum temperatures are increased rates of water loss and yellowing (Koike et al., 2011). Spinach quality is particularly sensitive to water loss, with $\approx 3 \%$ water loss making this commodity unmarketable (Bartz and Brecht, 2002; Sams, 1999). In our experiments, the water loss of the spinach stored in passive MAP remained below 3\% for the entire storage periods at 13 and $21^{\circ} \mathrm{C}$. Moreover, in both storage conditions, the spinach in MAP demonstrated significantly less water loss than the control treatment toward the end of storage. MAP reduces water vapor diffusion from plant tissues by maintaining a near saturated environment, leading to lower water loss (Serrano et al., 2006).

The textural properties of leafy green vegetables are directly related to water content and cell turgor (Sams, 1999); however, we did not detect differences in texture between the two treatments at either of the examined storage temperatures. Medina et al. (2012) also reported that spinach samples with differences in water content did not demonstrate differences in tenderness measured as maximum shear force $(\mathrm{N})$.

The color of the commodity is one of the main factors affecting consumer purchase decisions for fresh fruits and vegetables, and yellowing of leafy green vegetables is the leading reason for loss of acceptability (Shewfelt, 2002). Maintaining the green color of spinach directly translates into maintenance of its commercial value (Kaur et al., 2011). Generally, the ability of MA, controlled atmosphere, and MAP to slow down the rate of chlorophyll breakdown and yellowing has been reported for various green vegetables, such as amaranth (Amaranthus cruentus L.; Mampholo et al., 2015), broccoli (Brassica oleracea L. var. Italica; Serrano et al., 2006), pak-choy (Brassica rapa var. chinensis; O'Hare et al., 2000), and spinach (Suslow and Cantwell, 1999). Similarly, in our experiments the spinach stored in passive MAP maintained darker leaf color toward the end of the storage life at both temperatures compared with the spinach stored in the control bags, indicating a slower rate of yellowing. At $13{ }^{\circ} \mathrm{C}$, the color measurements were in accordance with the chlorophyll content and the spinach stored in MAP maintained higher amounts of chlorophyll. At $21{ }^{\circ} \mathrm{C}$, there were no differences in chlorophyll content between the two treatments. In some cases, the chlorophyll breakdown in spinach does not occur evenly over the leaf surface and yellowing occurs in a patchy pattern (Bergquist et al., 2006). This may lead to inconsistencies between colorimeter measurements and chlorophyll content, because the colorimeter measures only a portion of the spinach leaf, whereas the chlorophyll content analysis involves sampling a larger portion of the plant tissue (Proulx et al., 2010).

Postharvest quality does not only involve physical characteristics that are visible to the consumer, but also includes the nutritional content, flavor (Kader, 2000), and safety (Bruhn, 2002) of the commodity. In this study, there were no significant differences in total phenolic content, antioxidant capacity, and vitamin $\mathrm{C}$ content between the two treatments at either of the examined temperatures. Gil et al. (1999) similarly reported that spinach stored in a passive MAP of $6 \% \mathrm{O}_{2}$ plus $14 \% \mathrm{CO}_{2}$ at $10{ }^{\circ} \mathrm{C}$ did not differ in ascorbic acid content from spinach stored in nonmodified conditions. Mudau et al. (2018) reported that spinach stored in a MAP of 5\% $\mathrm{O}_{2}, 15 \% \mathrm{CO}_{2}$ maintained higher antioxidant activity compared with air storage at $4{ }^{\circ} \mathrm{C}$ but not at 10 or $20^{\circ} \mathrm{C}$. Our study did not examine the effect of passive MAP on the flavor characteristics of the stored spinach. Future studies should include sensory analysis and consumer testing if possible, because repeat purchases of fresh produce depend on flavor (Baldwin, 2002).

One of the limitations of this study was that we did not evaluate the effect of the studied MAP designs on food safety. When designing passive MAP applications for nonoptimum storage temperatures, the effect of the application on human pathogens should be considered. This is of particular importance for leafy greens because they have been closely associated with a multitude of severe disease outbreaks (Herman et al., 2015). Specifically, spinach was in the center of the deadly 2006 U.S. outbreak in which 100 hospitalizations and five deaths were caused by Shiga toxin-producing Escherichia coli O157 infections (Wendel et al., 2009). Storing produce at nonoptimum temperatures increases the risk for growth of human pathogens such as Salmonella and E. coli (Francis et al., 2012). Generally, MAP at nonoptimum temperatures has failed to limit the growth of human pathogens on leafy greens, including spinach (Oliveira et al., 2015). Although our results indicate that the utilization of passive MAP could be a potential solution for quality maintenance during nonoptimum 
temperature storage of spinach, the food safety aspect of this intervention should be investigated.

\section{Conclusion}

The results of this study show that the implementation of passive MAP for nonoptimum temperature storage has the potential to reduce postharvest losses of spinach by maintaining the quality and extending the storage life. The spinach stored in passive MAP at either 13 or $21^{\circ} \mathrm{C}$ demonstrated significantly higher overall quality during storage and longer storage life when compared with the control spinach stored in non-MAP produce bags. The implementation of passive MAP resulted in a slower rate of yellowing and water loss for the packaged spinach. Our results indicate that the passive MAP prolonged the "fresh life" of spinach, as indicated by the higher overall quality, and greener and more turgid leaves during storage compared with the control treatment. However, there were no statistical differences in the examined nutritional quality parameters between the two packaging treatments at either temperature. The effectiveness of the examined passive MAP design could be improved by using a film with higher WVTR, because decay caused by condensation was a limiting factor. Temperature control remains the most effective postharvest intervention for maintaining the quality and extending the shelf life of fresh produce. However, our results show that passive MAP can be a valuable tool for reducing the food losses occurring in small-acreage fruit and vegetable operations that have limited access to cooling. These growers tend to store their product in bulk (C.L. Rivard, personal communication), thus future research should examine a passive MAP design for storing spinach in bulk. Further research is needed for evaluating the effect of this passive MAP design on the control and growth of human pathogens like $E$. coli. The efforts for reducing FLW and satisfying global food demand should use innovative approaches, and passive MAP designed for nonoptimum temperatures is one of them.

\section{Literature Cited}

Agüero, M.V., M.V. Barg, A. Yommi, A. Camelo, and S.I. Roura. 2008. Postharvest changes in water status and chlorophyll content of lettuce (Lactuca sativa L.) and their relationship with overall visual quality. J. Food Sci. 73: S47-S55.

Bajji, M., J.M. Kinet, and S. Lutts. 2002. The use of the electrolyte leakage method for assessing cell membrane stability as a water stress tolerance test in durum wheat. Plant Growth Regulat. 36:61-70.

Baldassarre, V., G. Cabassi, and A. Ferrante. 2011. Use of chlorophyll as fluorescence for evaluating the quality of leafy vegetables. Aust. J. Crop Sci. 5:735-741.

Baldwin, E.A. 2002. Fruit flavor, volatile metabolism and consumer perceptions, p. 89-106. In: M. Knee (ed.). Fruit quality and its biological basis. CRC Press, Boca Raton, FL.
Bartz, J.A. and J.K. Brecht. 2002. Postharvest physiology and pathology of vegetables. CRC Press, Boca Raton, FL.

Beaudry, R.M. 2000. Responses of horticultural commodities to low oxygen: Limits to the expanded use of modified atmosphere packaging. Hort Technology 10:491-500.

Ben-Yehoshua, S., V. Rodov, S. Fishman, and J. Peretz. 1998. Modified-atmosphere packaging of fruits and vegetables: Reducing condensation of water in bell peppers and mangoes. Acta Hort. 464:387-392.

Benzie, I.F.F. and J.J. Strain. 1996. The ferric reducing ability of plasma (FRAP) as a measure of "antioxidant power": The FRAP assay. Anal. Biochem. 239:70-76.

Beretta, C., F. Stoessel, U. Baier, and S. Hellweg. 2013. Quantifying food losses and the potential for reduction in Switzerland. Waste Manag. 33:764-773.

Bergquist, S.Å.M., U.E. Gertsson, and M.E. Olsson. 2006. Influence of growth stage and postharvest storage on ascorbic acid and carotenoid content and visual quality of baby spinach (Spinacia oleracea L.). J. Sci. Food Agr. 86:346-355.

Brecht, J.K., K.V. Chau, S.C. Fonseca, F.A.R. Oliveira, F.M. Silva, M.C.N. Nunes, and R.J. Bender. 2003. Maintaining optimal atmosphere conditions for fruits and vegetables throughout the postharvest handling chain. Postharvest Biol. Technol. 27:87-101.

Bruhn, C.M. 2002. Consumer issues in quality and safety, p. 31-48. In: A.A. Kader (ed.). Postharvest technology of horticultural crops. University of California Agriculture and Natural Resources, Davis, CA.

Bunea, A., M. Andjelkovic, C. Socaciu, O. Bobis, M. Neacsu, R. Verhé, and J. Van Camp. 2008. Total and individual carotenoids and phenolic acids content in fresh, refrigerated and processed spinach (Spinacia oleracea L.). Food Chem. 108:649-656.

Cantor, A. and R. Strochlic. 2009. Breaking down market barriers for small and mid-sized organic growers. California Institute For Rural Studies, Davis, CA.

Cantwell, M., G. Hong, and X. Nie. 2010. Using tissue ammonia and fermentative volatile concentrations as indicators of beneficial and stressful modified atmospheres for leafy and floral vegetables. Acta Hort. 876:165-172.

Cantwell, M.I. and R.F. Kasmire. 2002. Postharvest handling systems: Flower, leafy, and stem vegetable, p. 423-435. In: A.A. Kader (ed.). Postharvest technology of horticultural crops. University of California Agriculture and Natural Resources, Davis, CA.

Cao, G., H.M. Alessio, and R.G. Cutler. 1993. Oxygen-radical absorbance capacity assay for antioxidants. Free Radic. Biol. Med. 14:303-311.

Charles, F., C. Guillaume, and N. Gontard. 2008. Effect of passive and active modified atmosphere packaging on quality changes of fresh endives. Postharvest Biol. Technol. 48:22-29.

Chiebao, H.P., J.R. Jenott, D.A. Unruh, S.E. Gragg, C.L. Rivard, and E.D. Pliakoni. 2018. Postharvest treatments to improve quality and safety of locally-grown vegetables stored at non-optimum temperatures. Acta Hort. 1194:1353-1360.

Clarke, R. 2011. Breatheway ${ }^{\circledR}$ membrane technology and modified atmosphere packaging, $\mathrm{p}$. 185-208. In: A.L. Brody, H. Zhuang, and J.H. Han (eds.). Modified atmosphere packaging for fresh-cut fruits and vegetables. Blackwell Publishing Ltd., Oxford, UK.

Conijn, J.G., P.S. Bindraban, J.J. Schröder, and R.E.E. Jongschaap. 2018. Can our global food system meet food demand within planetary boundaries? Agr. Ecosyst. Environ. 251:244-256.

D’Aquino, S., A. Mistriotis, D. Briassoulis, M.L. Di Lorenzo, M. Malinconico, and A. Palma. 2016. Influence of modified atmosphere packaging on postharvest quality of cherry tomatoes held at $20^{\circ} \mathrm{C}$. Postharvest Biol. Technol. 115:103-112.

Davis, K.F., J.A. Gephart, K.A. Emery, A.M. Leach, J.N. Galloway, and P. D'Odorico. 2016. Meeting future food demand with current agricultural resources. Glob. Environ. Change 39:125-132.

Domínguez, I., M.T. Lafuente, P. HernándezMuñoz, and R. Gavara. 2016. Influence of modified atmosphere and ethylene levels on quality attributes of fresh tomatoes (Lycopersicon esculentum Mill.). Food Chem. 209:211219.

Emanuel, M.A., P.F. Tennant, J.K. Brecht, and D.J. Huber. 2018. Effect of BreatheWay ${ }^{\circledR}$ microporous membrane on gaseous atmosphere and shelf life of ackee fruit. Acta Hort. 1225:173181.

Exama, A., J. Arul, R. Lencki, and Z. Li. 1993. Suitability of various plastic films for modified atmosphere packaging of fruits and vegetables: Gas transfer properties and effect of temperature fluctuation. Acta Hort. 343:175-180.

FAO. 2019. FAOSTAT, Crops. Food and Agriculture Organization. United Nations, Crop Database. <http://www.fao.org/faostat/en/\#data/ $\mathrm{QC}>$.

Fonseca, J.M. 2006. Postharvest quality and microbial population of head lettuce as affected by moisture at harvest. J. Food Sci. 71:M45M49.

Fonseca, S.C., F.A.R. Oliveira, J.K. Brecht, and K.V. Chau. 2005. Influence of low oxygen and high carbon dioxide on shredded Galega kale quality for development of modified atmosphere packages. Postharvest Biol. Technol. 35:279-292.

Francis, G.A., A. Gallone, G.J. Nychas, J.N. Sofos, G. Colelli, M.L. Amodio, and G. Spano. 2012 Factors affecting quality and safety of fresh-cut produce. Crit. Rev. Food Sci. Nutr. 52:595610.

Garrido, Y., J.A. Tudela, J.A. Hernández, and M.I. Gil. 2016. Modified atmosphere generated during storage under light conditions is the main factor responsible for the quality changes of baby spinach. Postharvest Biol. Technol. 114:45-53.

Ghidelli, C. and M.B. Pérez-Gago. 2018. Recent advances in modified atmosphere packaging and edible coatings to maintain quality of freshcut fruits and vegetables. Crit. Rev. Food Sci. Nutr. 58:662-679.

Gil, M.I. 2016. Preharvest factors and fresh-cut quality of leafy vegetables. Acta Hort. 1141:5764.

Gil, M.I., F. Ferreres, and F.A. Tomás-Barberán. 1999. Effect of postharvest storage and processing on the antioxidant constituents (flavonoids and vitamin $\mathrm{C}$ ) of fresh-cut spinach. $\mathrm{J}$. Agr. Food Chem. 47:2213-2217.

Gomes, C., R.G. Moreira, M.E. Castell-Perez, J. Kim, P. Da Silva, and A. Castillo. 2008. E-beam irradiation of bagged, ready-to-eat spinach leaves (Spinacea oleracea): An engineering approach. J. Food Sci. 73:E95-E102.

Greater Kansas City Food Hub Working Group. 2015. Kansas City food hub feasibility study. Kansas City, MO

Harrison, J.A., J.W. Gaskin, M.A. Harrison, J.L. Cannon, R.R. Boyer, and G.W. Zehnder. 2013. Survey of food safety practices on small to 
medium-sized farms and in farmers markets. J. Food Prot. 76:1989-1993.

Herman, K.M., A.J. Hall, and L.H. Gould. 2015. Outbreaks attributed to fresh leafy vegetables, United States, 1973-2012. Epidemiol. Infect. 143:3011-3021.

Huang, D., B. Ou, M. Hampsch-Woodill, J.A. Flanagan, and R.L. Prior. 2002. High-throughput assay of oxygen radical absorbance capacity (ORAC) using a multichannel liquid handling system coupled with a microplate fluorescence reader in 96-well format. J. Agr. Food Chem. 50:4437-4444.

Kader, A.A. 2013. Postharvest technology of horticultural crops-An overview from farm to fork. J. Appl. Sci. Technol. (Special Issue No.1):1-8.

Kader, A.A. 2002. Postharvest technology and biology: An overview, p. 39-47. In: A.A. Kader (ed.). Postharvest technology of horticultural crops. University of California Agriculture and Natural Resources.

Kader, A.A. 2000. Pre- and postharvest factors affecting fresh produce quality, nutritional value, and implications for human health, $\mathrm{p}$. 109-119. In: Intl. Congress Food Prod. and Th.

Kader, A.A. and M.E. Saltveit. 2003. Respiration and gas exchange, p. 7-29. In: J.A. Bartz and J.K. Brecht (eds.). Postharvest physiology and pathology of vegetables. Marcel Dekker Inc., New York, NY.

Kader, A.A. and C.B. Watkins. 2000. Modified atmosphere packaging - Toward 2000 and beyond. HortTechnology 10:483-486.

Kader, A.A., D. Zagory, and E.L. Kerbel. 1989. Modified atmosphere packaging of fruits and vegetables. Crit. Rev. Food Sci. Nutr. 28:1-30.

Kaur, P., D.R. Rai, and S. Paul. 2011. Quality changes in fresh-cut spinach (Spinacia oleracea) under modified atmospheres with perforations. J. Food Qual. 34:10-18.

Klimczak, I. and A. Gliszczynska-wiglo. 2015. Comparison of UPLC and HPLC methods for determination of vitamin C. Food Chem. 175:100-105.

Knewtson, S.J.B., E.E. Carey, and M.B. Kirkham. 2010. Management practices of growers using high tunnels in the central great plains of the United States. HortTechnology 20:639645.

Koike, S.T., M. Cahn, M. Cantwell, S. Fennimore, M. Lestrange, E. Natwick, R.F. Smith, and E. Takele. 2011. Spinach production in California. University of California, Agriculture and Natural Resources, Davis, CA.

Kou, L., Y. Luo, E. Park, E.R. Turner, A. Barczak, and W.M. Jurick. 2014. Temperature abuse timing affects the rate of quality deterioration of commercially packaged ready-to-eat baby spinach. Part I: Sensory analysis and selected quality attributes. Postharvest Biol. Technol. 91:96-103.

Lange, D.L. 2000. New film technologies for horticultural products. HortTechnology 10:487490.

Lim, L.T., I.J. Britt, and M.A. Tung. 1999. Sorption and transport of water vapor in nylon 6,6 film. J. Appl. Polym. Sci. 71:197-206.

Lipinsky, B., C. Hanson, J. Lomax, L. Kitinoja, R. Waite, and T. Seachinger. 2013. Reducing food loss and waste. Working paper. Installment 2 of "Creating a sustainable food future." World Resources Institute, Washington, DC.

Løkke, M.M., H.F. Seefeldt, and M. Edelenbos. 2012. Freshness and sensory quality of packaged wild rocket. Postharvest Biol. Technol. 73:99-106.
Mampholo, M.B., D. Sivakumar, and J. Van Rensburg. 2015. Variation in bioactive compounds and quality parameters in different modified atmosphere packaging during postharvest storage of traditional leafy vegetables (Amaranthus cruentus L and Solanum retroflexum). J. Food Qual. 38:1-12.

Maxwell, K. and G.N. Johnson. 2000. Chlorophyll fluorescence - A practical guide. J. Expt. Bot. 51:659-668.

Mc Carthy, U., I. Uysal, R. Badia-Melis, S. Mercier, C. O'Donnell, and A. Ktenioudaki. 2018. Global food security-Issues, challenges and technological solutions. Trends Food Sci. Technol. 77:11-20.

McGuire, R.G. 1992. Reporting of objective color measurements. HortScience 27:1254-1255.

Medina, M.S., J.A. Tudela, A. Marín, A. Allende, and M.I. Gil. 2012. Short postharvest storage under low relative humidity improves quality and shelf life of minimally processed baby spinach (Spinacia oleracea L.). Postharvest Biol. Technol. 67:1-9.

Morelock, T.E. and J.C. Correll. 2008. Spinach, p. 189-218. In: J. Prohens and F. Nuez (eds.). Vegetables I. Springer, New York, NY.

Mudau, A.R., P. Soundy, H.T. Araya, and F.N. Mudau. 2018. Influence of modified atmosphere packaging on postharvest quality of baby spinach (Spinacia oleracea L.) leaves. HortScience 53: 224-230.

Murmu, S.B. and H.N. Mishra. 2017. Engineering evaluation of thickness and type of packaging materials based on the modified atmosphere packaging requirements of guava (Cv. Baruipur). Lebensm. Wiss. Technol. 78: 273-280.

Myers, S.S., M. Smith, S. Guth, C. Golden, B. Vaitla, N. Mueller, A.D. Dangour, and P. Huybers. 2017. Climate change and global food systems: Potential impacts on food security and undernutrition. Annu. Rev. Public Health 38: 259-277.

Nunes, M. and J.P. Emond. 2002. Storage temperature, p. 209-228. In: J.A. Bartz, J.K. Brecht (eds.). Postharvest physiology and pathology of vegetables. CRC Press, Boca Raton, FL.

O'Hare, T.J., L.S. Wong, A. Prasad, and A.J. Able. 2000. Atmosphere modification extends the postharvest shelf-life of fresh-cut leafy Asian Brassicas. Acta Hort. 539:103-107.

Oliveira, M., M. Abadias, J. Usall, R. Torres, N. Teixidó, and I. Viñas. 2015. Application of modified atmosphere packaging as a safety approach to fresh-cut fruits and vegetablesA review. Trends Food Sci. Technol. 46:1326.

Ou, B., M. Hampsch-Woodill, and R.L. Prior. 2001. Development and validation of an improved oxygen radical absorbance capacity assay using fluorescein as the fluorescent probe. J. Agr. Food Chem. 49:46194626.

Pandjaitan, N., L.R. Howard, T. Morelock, and M.I. Gil. 2005. Antioxidant capacity and phenolic content of spinach as affected by genetics and maturation. J. Agr. Food Chem. 53:8618 8623.

Park, J., J. Kyoung, and C. Jeong. 2006. Effect of active modified atmosphere packaging and storage temperature on the quality of spinach. Hort. Environ. Biotechnol. 47:5-9.

Porat, R., A. Lichter, L.A. Terry, R. Harker, and J. Buzby. 2018. Postharvest losses of fruit and vegetables during retail and in consumers' homes: Quantifications, causes, and means of prevention. Postharvest Biol. Technol. 139: 135-149.
Prakash, A., A.R. Guner, F. Caporaso, and D.M Foley. 2000. Effects of low-dose gamma irradiation on the shelf life and quality characteristics of cut romaine lettuce packaged under modified atmosphere. J. Food Sci. 65:549-553.

Prior, R.L., H. Hoang, L. Gu, X. Wu, M. Bacchiocca, L. Howard, M. Hampsch-Woodill, D. Huang, B. $\mathrm{Ou}$, and R. Jacob. 2003. Assays for hydrophilic and lipophilic antioxidant capacity (oxygen radical absorbance capacity (ORACFL)) of plasma and other biological and food samples. J. Agr. Food Chem. 51:3273-3279.

Proulx, E., Y. Yagiz, M. Cecilia, and J.P. Emond. 2010. Quality attributes limiting snap bean (Phaseolus vulgaris L.) postharvest life at chilling and non-chilling temperatures. HortScience 45:1238-1249.

Prusky, D. 2011. Reduction of the incidence of postharvest quality losses, and future prospects. Food Secur. 3:463-474.

Rodriguez-Aguilera, R. and J.C. Oliveira. 2009. Review of design engineering methods and applications of active and modified atmosphere packaging systems. Food Eng. Rev. 1:66-83.

Rux, G., O.J. Caleb, M. Geyer, and P.V. Mahajan. 2017. Impact of water rinsing and perforationmediated MAP on the quality and off-odour development for rucola. Food Packag. Shelf Life 11:21-30.

Sams, C.E. 1999. Preharvest factors affecting postharvest texture Postharvest Biol. Technol. 15:249-254.

Sandhya. 2010. Modified atmosphere packaging of fresh produce: Current status and future needs. LWT - Food Sci. Technol 43:381-392.

Schofield, R.A., J.R. DeEll, D.P. Murr, and S. Jenni. 2005. Determining the storage potential of iceberg lettuce with chlorophyll fluorescence. Postharvest Biol. Technol. 38: 43-56.

Serrano, M., D. Martinez-Romero, F. Guillén, S. Castillo, and D. Valero. 2006. Maintenance of broccoli quality and functional properties during cold storage as affected by modified atmosphere packaging. Postharvest Biol. Technol. 39:61-68.

Shewfelt, R.L. 2002. Color, p. 294-303. In: J.A. Bartz and J.K. Brecht (eds.). Postharvest physiology and pathology of vegetables. CRC Press, Boca Raton, FL.

Shewfelt, R.L., S.E. Prussia, and S.A. Sparks. 2014. Challenges in handling fresh fruits and vegetables, p. 11-30. In: W.J. Florkowski, R.L. Shewfelt, B. Brueckner. and S.E. Prussia (eds.). Postharvest handling: a systems approach. Academic Press Inc., Cambridge, MA.

Singleton, V.L. and J.A.J. Rossi. 1965. Colorimetry of total phenolics with phosphomolybdicphosphotungstic acid reagents. Amer. J. Enol. Viticult. 16:144-158.

Suslow, T.V. and M. Cantwell. 1999. Spinach: Recommendations for maintaining postharvest quality. UC Davis Vegetable Produce facts. $<$ http://postharvest.ucdavis.edu/Commodity_ Resources/Fact_Sheets/Datastores/Vegetables_ English/?uid=32\&ds=799>.

Tano, K., M.K. Oulé, G. Doyon, R.W. Lencki, and J. Arul. 2007. Comparative evaluation of the effect of storage temperature fluctuation on modified atmosphere packages of selected fruit and vegetables. Postharvest Biol. Technol. 46: 212-221.

Tudela, J.A., A. Marín, Y. Garrido, M. Cantwell, M.S. Medina-Martínez, and M.I. Gil. 2013. Offodour development in modified atmosphere 
packaged baby spinach is an unresolved problem. Postharvest Biol. Technol. 75:75-85.

Watkins, C.B. 2000. Responses of horticultural commodities to high carbon dioxide as related to modified atmosphere packaging. HortTechnology 10:501-506.

Wellburn, A.R. 1994. The spectral determination of chlorophylls a and $b$, as well as total carotenoids, using various solvents with spectrophotometers of different resolution. J. Plant Physiol. 144:307-313.
Wendel, A.M., D. Hoang Johnson, U. Sharapov, J. Grant, J.R. Archer, T. Monson, C. Koschmann, and J.P. Davis. 2009. Multistate outbreak of Escherichia coli O157:H7 infection associated with consumption of packaged spinach, AugustSept. 2006: The Wisconsin investigation. Clin. Infect. Dis. 48:1079-1086.

Wilson, M.D., R.A. Stanley, A. Eyles, and T. Ross. 2019. Innovative processes and technologies for modified atmosphere packaging of fresh and fresh-cut fruits and vegetables. Crit. Rev. Food Sci. Nutr. 59:411-422.
Yaptenco, K.F., J.G. Kim, and B.S. Lim. 2007. Gas transmission rates of commercially available polyethylene and polypropylene films for modified atmosphere packaging. Philipp. Agr. Sci. 90:22-27.

Zagory, D. and A.A. Kader. 1988. Modified atmosphere packaging of fresh produce. Food Technol. 42:70-77.

Zhang, M., G. Xiao, and V.M. Salokhe. 2006. Preservation of strawberries by modified atmosphere packages with other treatments. Packag. Technol. Sci. 19:183-191. 